\title{
Implementing Cognitive Strategy Instruction to Improve the Actual Intellectual Abilities of the Undergraduate Students with Cognitive Expression Difficulties
}

\author{
Martini Jamaris \\ Universitas Negeri Jakarta \\ Email: martinijamaris@unj.ac.id
}

\begin{abstract}
This research aims to find out the effectiveness of cognitive strategy instruction for improving intellectual abilities of undergraduate students with cognitive expressing difficulties, especially in actualizing their thinking abilities starting from lower order thinking up to higher order thinking. Therefore, the cognitive strategy instructional design based on Bloom's Taxonomy is constructed in order to accomplish the research objectives. This research uses mixed method approach entailing the implementation of two research methods. The first is qualitative method which aims to get information of the cognitive strategy in instructional process. The second is quantitative method which is used to measure the students' improvement in cognitive abilities or actual intellectual abilities after participating in cognitive strategies instruction. Research implementation is divided into three stages. The first stage is needs assessment, in which the students' thinking / cognitive skill abilities are observed and measured in order to have evidence whether or not they have cognitive expression difficulties. The second stage is to use the needs assessment results in designing cognitive strategy instruction. The third stage is the implementation of the instructional design. There are 20 undergraduate students taking part in this research who are selected by purposive sampling technique. The results revealed that cognitive strategy instruction effectively improves the actual intellectual abilities of students with cognitive expression difficulties. Qualitatively, the students feel very satisfied with their actual intellectual abilities.
\end{abstract}

Keywords: actual intellectual abilities, cognitive strategy instruction, students with cognitive expression difficulties

\section{INTRODUCTION}

Undergraduate students are students who just move from being teenagers to being young adults. Adult years hold a great potential for intellectual, emotional and even physical development. There are important advances that occur during young adulthood (20-40 years old) to middle adult age (40-60 years old). However, some students reported that they feel exhausted caused by academic work-related stress (Jamaris, 2014). It is because they are in the process of adapting themselves to higher educational world.

Intellectually, the higher order educational instruction focuses on the actualization of thinking abilities, especially in higher order thinking abilities. These abilities involve critical thinking which consists of the ability in actualizing analytical thinking, evaluative thinking as well as creative thinking (Jamaris, 2014). The results of observation conducted by the researcher revealed that some of the undergraduate students had difficulties in actualizing their thinking abilities, especially difficulties in cognitive expression.

These abilities move from lower order of thinking to higher order of thinking. Cognitive abilities influence academic achievement (Morales, Calvo, \& Bialystok 2013). It is because the cognitive process linked to the frontal lobe function or executive function involves thinking abilities. The thinking abilities consists of critical thinking abilities, which include problem solving abilities, perception, memory and language abilities. Therefore, y problems dealing with the above frontal lobe abilities can cause any forms of cognitive actualization problems. In other words, the individual concerned has difficulties in cognitive expression.

Another reason related with the problems of cognitive expression problems is difficulties in concentration. It is similar to attention as the key of mental activities which drive brain activities, especially in the frontal lobe area to anticipate activities in planning any needed actions. According to the result of observations, inabilities in doing these process can be reflected in the form the students' inabilities in doing higher order thinking, such as designing mind map of the course materials that have been read by the students and explaining the mind map that they have made . All of those are related with cognitive strategy abilities. Cognitive strategy is a mental routine or procedure aids in performance of specific cognitive tasks (Dole, Nokes, \& Drits, 2009) 
Based on the logical reasoning which has been described previously, it is important to conduct research aiming to overcome cognitive expression problems of the undergraduate students. Among them is dealing with improving actual intellectual abilities of the undergraduate students with cognitive expression difficulties. Intellectual abilities are reflected in human cognitive abilities. These abilities are in line with the abilities in thinking which move from lower order thinking to higher order thinking.

Based on the previous description, some research questions are formulated as follows: (1) How to design cognitive strategy instruction?; (2) How to implement cognitive strategy instruction to improve intellectual actual abilities of undergraduate students with cognitive expression difficulties (?); (3) Do the intellectual actual abilities of the undergraduate students improve after participating the cognitive strategy instruction?

Intelligence is defined as a general mental ability for reasoning, problem solving and learning. Intelligence involves cognitive function as perception, attention, memory, language and planning (Anderson \& Roit, 1993). Snow and Lohman, 1984 regarded intellectual ability as the acquired repertoire of general cognitive skills that is available to a person at a particular point of time (Prins, Veenman, \& Elshout, 2006) .

Intellectual abilities refer to general intellectual functions and cognitive abilities. General intellectual function dealt with globa or ove all level of intelligenc , often referred to as IQe(intelligencetquotient). Cognitive abilities involving specific abilities of intelligence are skills that make up an individual general intelligence. Therefore, intelligence is composed by many abilities (Ortiz, Lella, \& Canter, 2010). Cognitive abilities cover some of the following categorie : numerical, verbal, spatial and mechanical reasoning. In line with the previous explanatio, intelligence requires a simple assembly and tuning of many small units of knowledge that in total produce complex cognition or intelligence.

Cognitive is related to any mental activities in processing received information which involves perception and sensory registration, storage, and related processeseincluding elaboration, manipulation, selection and storage and output processes which require production of appropriate responses ( Bunce, 2016, Jamaris, 2014). All of the information processed requires mental activitiesewhich comprise of attention mechanisms for bringing the information in, working memory for actively manipulating the information, and long term memory for passively holding the information so it can be used in the future. In lind withtthis, mental abilities also requirg basic information processing components.
Cognitive expression difficulties are related to difficulties in doing mental processing in taking, organizing, and producing any response matched to the information manipulation process. Difficulties in these areas are reflected in learning difficulties, such a, arithmetic learning difficulties which ish caused by working memory impairment, (McLean \& Hitch, 1999). In accordance with this problem,lexhaustion in each individual includes specific problem in concentration accompaniedhby difficulties in executive control over attention. Executive control refers to a set of cognitive process underlying voluntary and effortful regulation of perception and motor process in order to adaptively deal with problems and change task demands (Linden et al., 2005). Consequently, the inability to do cognitive tasks in concentration an thinking is the portrayal of impaired executive contro, which might be related to work performance failur or studens failure in learning performances.

Strategy instruction has transformed into so many strategies used in teaching.bBooks and articleshabout instruction strategies have been discussed by a lot of researchers, among them are (Leinhardt \& Greeno, 1986; Clark \& Graves, 2005; Mayilvaganan and Kalpanadevi, 2015).

Cognitive strategy instruction lies in the field of psychology (Dole, Nokes, \& Drits, 2009).cSince then, cognitive psychologists who focused on the mind exclusively thoughg about how humans process, organize and store incoming information in memory. According to cognitive psychologist, cognitive strategy is the mental procesg that occurs in the mindgto handle incoming informatio, as well a, to monitog and evaluatg the understanding of information (Greeno, Collins, \& Resnick, 1996; van Dijk \& Kintsch, 1983). Therefore, cognitive strategy is a mental routine procedure for accomplishing a cognitive goal in processing information.

Cognitive strategy involves thinking activities, srarting from lower order thinking up to higher order thinking. In line with the strategy, Bloom's research results ecame out with six level of cognitive skills which include: knowledge is thelfundamental of cognitive skill which refers to the retention of specific discrete pieces of informatio einvolving knowledge of terminolog, or specific facts, knowledge of specific ways and mean, and knowledge of field, such a, principle, generalization, theories and structures in universal and abstractions (Krathwohl \& Kaiser, 2004; comprehensio, the next level of Bloom's taxonomy, showd the ability in paraphrasing the information in their own word, classifying items in group, comparing and contrasting items with similar entities, or explaining a principle to other; application involves the ability to use best practice in doing activities. 


\section{Figure 1. Implementation of Martini Jamaris Action Research Model}

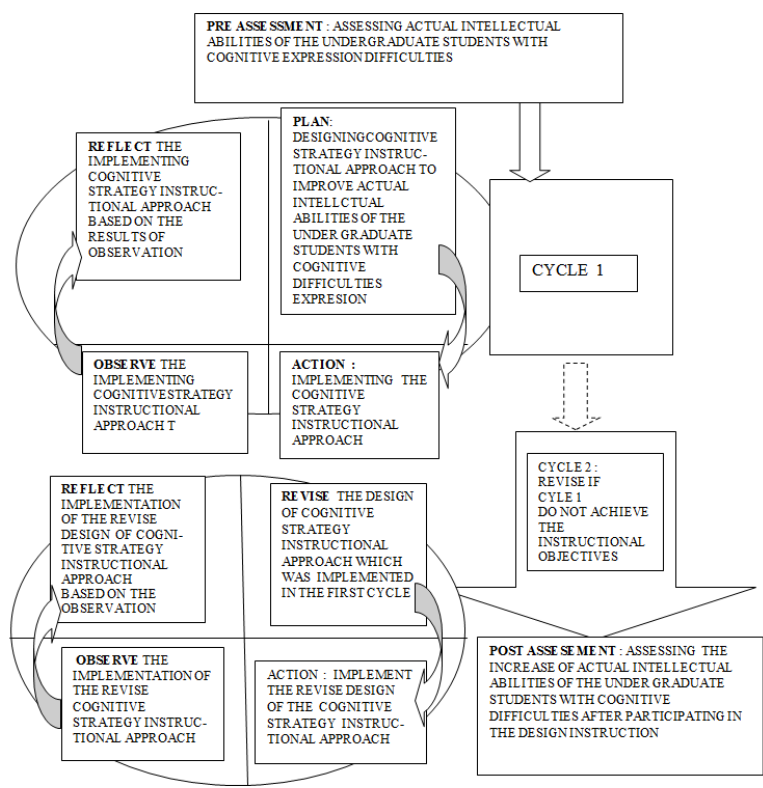

Source: Jamaris (2014), Formal Multiple Intelligences Assessment Instruments for The 4-6 Years Old Children.

Furthermore, the cognitive level moves to higher order thinking abilities involvine analysis which refees to critical thinkinghand can bedbroken down into the ability to distinguish between fact and opinio, and identifg the claims upon an argument, breag down information intosits components in order to identify the most appropriate search terms; synthesi h defined as the ability to formulatg wel built questions or planed action to solve problem in accordance to the informed facts or opinion (Krathwohl \& Kaiser, 2004); t create is placed as the higher level of cognitive taxonom, which consists of generating, planning and producin,; evaluation refers to judge relevance result of application of the specific planed action.

In line with cognitive strategy instruction, an instructional design is constructed based on a systematic design which include : learning objectives, learning materials, learning process and learning evaluation, as well as, learning fee back (Jamaris, 2016).

Based on thetabove description of cognitive level, it can be concluded that cognitive strategy refers to different cognitive tasks of implementation in solving problems. The cognitive tasks may involve lower order thinking and higher order thinking which are operated based on the type of problems. Therefore, cognitive strategy instruction is a type of instruction aimd to empower the students' cognitive abilities which directly improve the students actual intellectual abilities.

\section{METHOD}

Based on the need in implementing cogtitive strategy to improve actual intellectual abilities of undergraduate students with cognitive expression difficulties, the research problems are formulated as follow: (1) How to design the cognitive strategy instructio; (2) How to implement cognitive strategy instruction to improve actual intellectual abilities of the undergraduate students with cognitive expression difficultie?; (3) Do the actual intellectual abilities of the undergraduate students improve after participating the cognitive strategy instruction?

The Rresearch method used in this study is designed based on the research question, in whic, it requires two kinds of research methods; quantitative research method and qualitative research method. Therefore, the research methos used in this study is mix method. Implementation of the mix method research is in the form of action research. The action research method was used based on Kemmish and Tagart action research mode as well a, Bachman's action research spiral which had been modified by Jamaris (2016), as shoen in figure 1.

In accordance to the mix method research applied in this research, data collection and data analysisewere conducted quantitatively and qualitattvely.

Quantitative data was collected by using pre test and post test of the actual intellectual abilities of the undergraduate students. In line with the need of the research, the pre-test and post test items were constructed based on Bloom'sitaxonomy. It is because theitaxonomydreflects the cognitive actual abilities of the students and it directly represents the actual intellectual abilities of the undergraduate students with cognitivenexpression difficulties.

Qualitative data was collected by doing observation on the overt behaviors showed by the students during instructional process which aimed to improve their actual intellectual abilities. Therefore, field notesswere constructe, in orde, to record all the students' overt behaviors. In line with this activity data codes were also developed systematically to support qualitative data analysis entailing to develop semantics relation of the qualitative data. Therefore, theeessence and the meaning of the data can be constructe, in orde, to answer the research questions. A long with these activites triangulations were also applied.

Population of the research was undergraduate students of Special Education Program of FIP UNJ. The sample of researchswas selected by applying purposive research sample. The reason underlined the selection of sample technique is because the sample has to be decided based on need assessment resultsgfocusing on whether or not the undergraduate students have cognitive expression difficulties. 


\section{Figure 2. Actual Intellectual Abilities' Score Improvement of the Students with Cognitive Expression Difficulties.}

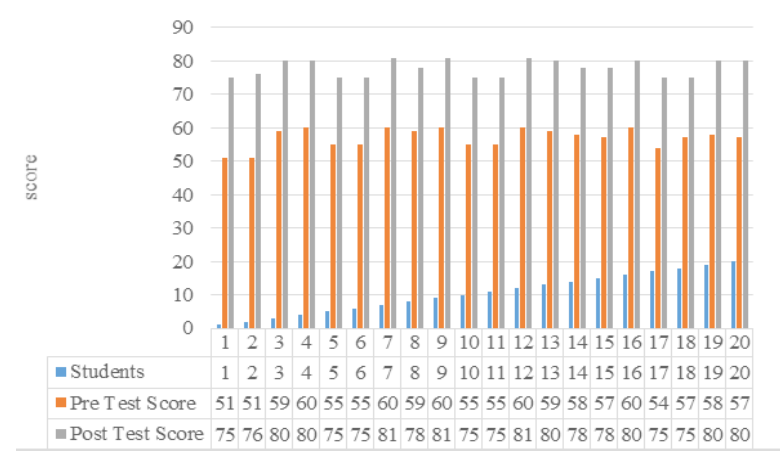

Figure 3. Improvement Quality of Actual Intellectual Abilities of the Undergraduate Students with Cognitive Expression Difficultes

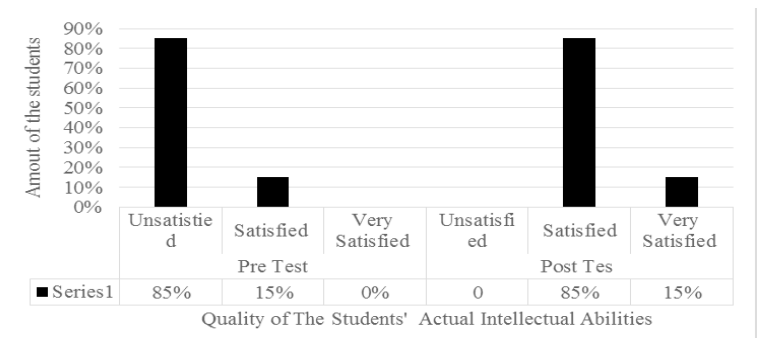

Based on thesprevious description, it is informedm that instructional design of cognitive strategy instruction is needed to develop the research process. The instruction is designed systematically at least consisting of instructional objectives, instructional contents, instructional processes, and instructional evaluation (Dick \& Carey, 1985). All the instructional design elements are involved in Bloom's taxonomy which aimed to improve cognitive abilities or actual intellectual abilities of the students with cognitive expression difficulties.

\section{FINDINGS AND DISCUSSION}

\section{Findings}

Quantitative data analysis based on pre-test score and post-test score of the under- graduate student are compared. The comparative result of the two kinds of score showed the improvement of the actual intellectual abilities of the undergraduate students with cognitive expression difficulties. It can be analyzed from of the score of students; cognitive abilities with average pre-test score 59.9 to 74,15 on post-test. Therefore, the students' score increased $123.80 \%$ as described in the figure 2 .

The qualitative data analysis showed the number of undergraduate students who have satisfying score to very satisfying score on pre-test and post-test, as showed in the following figure. From the table, it can be seen that before participating in the cognitive strategies instruction, $85 \%$ of the students were unsatisfied, $15 \%$ of them were satisfied, but none of the students felt very satisfied. The students' scores improved after participating in cognitive strategies instruction. After the instruction it was found that 0 $\%$ of the students felt unsatisfied, $85 \%$ were satisfied and $15 \%$ were very satisfied. Figure 3 shows the related description.

\section{Discussion}

The research results revealed that before the undergraduate students with cognitive expression difficulties participated in cognitive strategy instruction, the cognitive abilities of $85 \%$ of the students were below average, supported with the fact that their performance in processing information were unsatisfying, It indicated that their ability to perform cognitive skills to operate lower order thinking up to higher order thinking are also average. The actual intellectual abilities of the students improved after participating in the cognitive instructional strategies in which $85 \%$ of the students were satisfied, and none of them were unsatisfied. The results of the research in the implementation of cognitive strategy instruction to improve the actual intellectual abilities of undergraduate students with cognitive expression difficulties are effective to reach the instruction objectives.

The research results are supported by the results of other researches. Among them state that the objectives of cognitive strategy instructions wereconstructed on Blooms' taxonomy which includes lower order thinking abilities involving the abilities to know, to understand and to apply knowledge up to higher order thinking abilities. It requires the abilities to analyze, to synthesize, to evaluate any information received by senses or sensor-motoric, and to create (Jshabatu, 2018), such as to create action plans to solve any kinds of problems. The Bloom's taxonomy is effective to improve the students' cognitive abilities. The research results are also supported by other researches in the same field. The Bloom's taxonomy of cognitive learning objectives accommodates the mental processing that occurs in the mind to handle incoming information, as well as, for monitoring and evaluating the understanding of information (Greeno, Collins, \& Resnick, 1996; van Dijk \& Kintsch, 1983; Anwar \& Sohail, 2014). Bloom's taxonomy is hierarchical, meaning that learning at higher level depends on having attained prerequisite knowledge and skills at lower level (Jshabatu, 2018). 


\section{CONCLUSION}

Based on the research results, it can be concluded that the implementation of cognitive strategy instructional model is effective to improve the actual intellectual abilities of students with cognitive expression difficulties. The conclusion is also supported by the findings of other researchers.

\section{REFRENCES}

Anderson, V., \& Roit, M. (1993). Planning and implementing collaborative strategy instruction for delayed readers in grades 6-10. The Elementary School Journal, 94(2), 121-137.

Anwar, H. N., \& Sohail, M. M. (2014). Assessing the learning level of students through Bloom's taxonomy in higher education in Punjab. Journal of Educational and Social Research, 4(3), 83-87.

Bunce, W. A. (2016). Information Processing Theory of Development: A Cognitive Theory Approah. University of West Georgia.

Clark, K. F., \& Graves, M. F. (2005). Scaffolding students' comprehension of text. The Reading Teacher, 58(6), 570-580.

Dick, W., \& Carey, L. (1985). The systematic design of instruction 2nd. Ed. Glenview, IL: Scott, Foresman and Company.

Dole, J. A., Nokes, J. D., \& Drits, D. (2009). 16 Cognitive Strategy Instruction. Handbook of research on reading comprehension, 347.

Greeno, J. G., Collins, A. M., \& Resnick, L. B. (1996). Cognition and learning. Handbook of educational psychology, 77, 15-46.

Jamaris, M. (2014). Formal multiple intelligences assessment instruments for 4-6 years old children. American Journal of Educational Research, 2(12), 1164-1174.
Jamaris, M. (2016). The Impacts Of The Graduate Students'Self-Evaluations To Their Achievements. International Journal of Multidisciplinary Research And Development, 3(5), 242-249.

Jshabatu. (2018). Using Bloom's Taxonomy to Write Effective Learning Objective. Taching Innovation \& Padagogical Support.

Krathwohl, M. D., \& Kaiser, J. L. (2004). Chemokines promote quiescence and survival of human neural progenitor cells. Stem Cells, 22(1), 109-118.

Leinhardt, G., \& Greeno, G. J. (1986). Cognitve Skill of Teaching. Journal of Educational Psychology. 78(2), 75-81.

Linden, D. V. D., Keijsers, G. P., Eling, P., \& Schaijk, R. V. (2005). Work stress and attentional difficulties: An initial study on burnout and cognitive failures. Work \& Stress, 19(1), 23-36.

Mayilvaganan, M., \& Kalpanadevi, D. (2015). Cognitive Skill Analysis for Students through Problem Solving Based on Data Mining Techniques. Procedia Computer Science, 47, 62-75.

McLean, J. F., \& Hitch, G. J. (1999). Working memory impairments in children with specific arithmetic learning difficulties. Journal of experimental child psychology, 74(3), 240-260.

Morales, J., Calvo, A., \& Bialystok, E. (2013). Working memory development in monolingual and bilingual children. Journal of experimental child psychology, 114(2), 187-202.

Ortiz, S. O., Lella, S. A., \& Canter, N. A. (2010). Intellectual Ability and Assessment: A Primer for Parents and Educators. Bethesda: National Association of School Psychologists, 1-4.

Prins, F. J., Veenman, M. V., \& Elshout, J. J. (2006). The impact of intellectual ability and metacognition on learning: New support for the threshold of problematicity theory. Learning and instruction, 16(4), 374-387.

Van Dijk, T. A., \& Kintsch, W. (1983). Strategies for discourse comprehension. Orlando, FL: Academic Press. 